2017-07-11

\title{
Improving the Representation of the Fragility of Coastal Structures
}

\author{
Jane, $R$
}

http://hdl.handle.net/10026.1/13855

$10.1061 / 9780784480304.055$

Coastal Structures and Solutions to Coastal Disasters 2015

American Society of Civil Engineers

All content in PEARL is protected by copyright law. Author manuscripts are made available in accordance with publisher policies. Please cite only the published version using the details provided on the item record or document. In the absence of an open licence (e.g. Creative Commons), permissions for further reuse of content should be sought from the publisher or author. 


\title{
Improving the representation of the fragility of coastal structures.
} R. Jane ${ }^{1}$, D. Simmonds ${ }^{1}$, J. Simm ${ }^{2}$, B. Gouldby ${ }^{2}$, A. Raby ${ }^{1}$ and L. Dalla Valle $^{3}$.

${ }^{1}$ University of Plymouth, School of Marine Science and Engineering, Drakes Circus, Plymouth, PL4 8AA, UK.

${ }^{2}$ HR Wallingford, Howbery Business Park, Crowmarsh Gifford, Wallingford, OX10 8BA, UK.

3 University of Plymouth, School of Computing, Electronics and Mathematics, Drakes Circus, Plymouth, PL4 8AA, UK.

\begin{abstract}
Information regarding the likelihood of structural failure of flood defences forms an essential part of any flood risk analysis (FRA). At present, when conducting FRA the probability of a defence failing is expressed conditionally upon a single variable either a hydraulic loading or a composite variable - a function of several hydraulic loading variables. A methodology has recently been proposed for simulating realistic sets of extreme nearshore sea conditions that comprises all of the hydraulic loading variables that can combine to produce an extreme sea state. By acting as the boundary conditions for a coastal FRA, the methodology has opened up the possibility of incorporating more detailed representations of the susceptibility of a coastal defence structure to failure into such analyses. It is anticipated that this more accurate description of a structure's likelihood of failure will ultimately lead to more accurate flood risk estimates. In this paper, the newly derived fragility representations are introduced before the difference/improvement in their description of a defences' susceptibility to failure is assessed by comparing the annual failure probabilities given by the new and existing representations.
\end{abstract}

\section{Introduction}

The probability that a defence fails when subjected to a given loading is referred to as its fragility. Information on a structures fragility is required throughout a structures lifetime. In the design phase, such information can be used to determine the properties of a structure such as its crest elevation and material composition. Post construction the fragility of the structure needs to be continually assessed in order to determine the pace and scale of any remediation work that is required. Finally, near the end of a structure's design life it can be used to among other things evaluate its residual life capacity and if appropriate dictate the re-engineering necessary for extending its life capacity. Over the past decade or so as the UK has moved to risk based approach to flood engineering (Sayers et al., 2002) it has also become a central concept in flood risk analysis (FRA).

The UK Environment Agency, the government agency whom are primarily responsible for managing the UK's flood risk, currently adopt a system wide 
approach (Hall et al., 2003; Sayers and Meadowcroft, 2005; Gouldby et al., 2008) to FRA through the Source-Pathway-Receptor (SPR) model (Sayers et al., 2002). It decomposes the flooding process into a sequence of steps from which the flood risk of a given area, in terms of its expected annual damage, can be determined. It entails imposing the estimated hydraulic loading scenarios on to the flood defence structures from which the amount of flood water entering receptor areas behind the defences is calculated. From this the "consequence" of a scenario can be calculated by relating the flood water volumes to, for instance depth of flooding and thus economic damage. Once this is repeated for a large number of suitable extreme events that have been sampled from the relevant population the estimate of flood risk can be obtained. The consequences of an event will strongly depend on the volume of water that will enter the flood plain for a given event. The water can enter the flooding area by either overtopping the defence or by flowing through the defence if it fails. A significantly larger volume can be expected to enter the flooding area should the defence fail thus it is vital to accurately assess the probability of a defence failing, if accurate flood risk is to be achieved. The probability of the defence failing given that it is subjected to a particular loading is referred to as its fragility. An assessment of the relevant defences' fragility forms the pathway part of the SPR model. Although clearly a vital component in determining the flood risk it is currently the least developed component of the SPR model.

In the existing approach fragility is represented by fragility curves (USACE , 1996, 2000; Sayers and Meadowcroft, 2005; Schultz et al., 2010) where the probability of the defence failing is expressed conditionally on a single loading variable, such as water level. By considering the most likely failure mechanism(s) that a defence will suffer the Environment Agency have developed generic fragility curves for 61 flood defence assets that are typical of those found in the UK (Defra EA, 2005). The deterioration of each type of structure was considered when generating the curves through a set of visually assigned condition grades which range from 1 ('very good') to 5 ('very poor'), thus there are 5 curves associated with each asset type to represent the different condition grades. These generic curves are predominantly used in larger scale FRA where the number of flood defence assets is large. Smaller scale FRA offers the opportunity for site specific curves to be considered which can provide a more accurate assessment of the structure's fragility than these general curves. They are able to encompass any additional failure mechanisms that a structure is found to be susceptible to after more detailed analysis of the structure as well as any site specific factor may influence its fragility, they can be generated by the approach outlined in (Simm et al., 2008).

Due to restrictions in modelling the dependence structure between the hydraulic loading variables during extreme events the definition of fragility has been restricted to a single loading. In general when representing fragility the hydraulic load is defined as the water level in fluvial locations and overtopping discharge when in a coastal setting. In fluvial situations the hydraulic load can be well defined in terms of the single parameter namely water level however in coastal locations this restriction can lead to an inaccurate description of 
the fragility of a structure. A consequence of there being an infinite number of combinations of water level, wave height and wave period which give the identical overtopping discharge volumes and the often complex relationship between these loadings and the chance of a structure failing. This results in events with the same overtopping discharge offering very different probabilities of certain failure mechanisms occurring. Consequently it is not likely to be possible to accurately represent the probability of defence failing conditionally upon a single amalgamated measure. Advancements in the modelling of the loadings placed on a defence means that each of the hydraulic loadings can now be explicitly considered when conducting system wide FRA thus allowing the incorporation of more sophisticated descriptions of the fragility into such analyses.

The purpose of this paper is to introduce a new representation of fragility and provide a preliminary assessment of its performance. The paper is laid out as follows. Firstly, a case study defence where the new methodology for describing a defences fragility has been implemented is introduced. The existing fragility representations for the defence are then examined before the new representation introduced. The extreme offshore conditions in the region where the defence is located are modelled and sets of extreme offshore loading events are simulated. Theses conditions are then propagated into the nearshore, by a combination of a physics based model and a meta-model, from which the annual failure probabilities can be computed for each representations. By comparing these estimates an indication as to the improvement in the assessment of the fragility upon the existing representations given by the new one can be determined and appropriate conclusions drawn.

\section{Case Study Site: Chesil Cove}

Chesil beach (Dorset, UK) is one of three major shingle structures in Britain. Part of the Jurassic Coast World Heritage Site, it consists of a gravel beach with an average width of $160 \mathrm{~m}$ that stretches approximately $28 \mathrm{~km}$ from the Isle of Portland to West Bay. At its eastern end the beach runs adjacent to the main road route onto the Isle of Portland before it curves to form Chesil Cove where the low lying village of Chiswell is found. Since the consequences of either area being flooded are severe, a range of coastal defence measures have been put in place to reduce the risk of such an event occurring. Initially a reinforced concrete seawall was constructed between 1958 and 1965 within Chesil cove to protect the village. After flooding events in 1978 \& 1979, it was subsequently upgraded during the 1980's to include a wave retaining wall at the back of the esplanade to reduce wave overtopping, as well as $5 \mathrm{~m}$ long steel toe piles at its base in an attempt to prevent any undermining. A concrete apron along part of its frontage to induce wave breaking and reduce the potential for toe scour was also constructed. In the same period a $450 \mathrm{~m}$ stretch of gabions and gabion mattresses were laid to the west of the seawall in order to raise and strengthen the beach and ultimately prevent it breaching. The seawall suffered substantial damage to its toe during a near failure event on the 5th February 2014, Figure 1. 


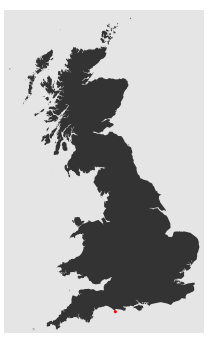

(a) Location of seawall

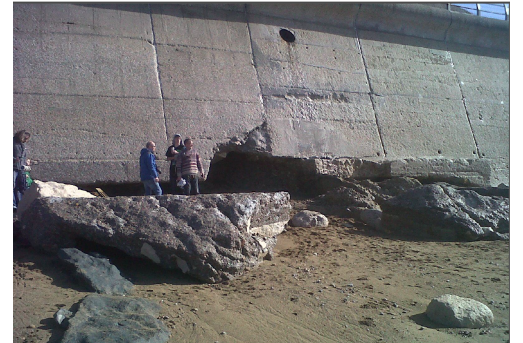

(b) Structural damage suffered at its toe during an event on the 5 th February 2014 is clearly visible.

Figure 1: Chesil Cove seawall.

\section{Existing Representation}

The seawall at Chesil cove is classified as a vertical retaining wall. The generic fragility curve for such a defence which forms the pathway section of existing FRA are shown in Figure 2. For this particular asset type toe scour is considered the most relevant failure mechanism. The curves are constructed on the basis of the scour predictor derived by Sutherland et al. (2006). Although it is considered one of the most comprehensive scour predictors derived to date it is formulated on the basis of laboratory experiments and field measurements where a sandy beach adjoins a vertical seawall. It can for seawalls where a shingle beach is located adjacent to the structure, such as at Chesil Cove, therefore be expected, at best, to give a conservative estimate of the scour depth for a particular set of hydraulic loading conditions.

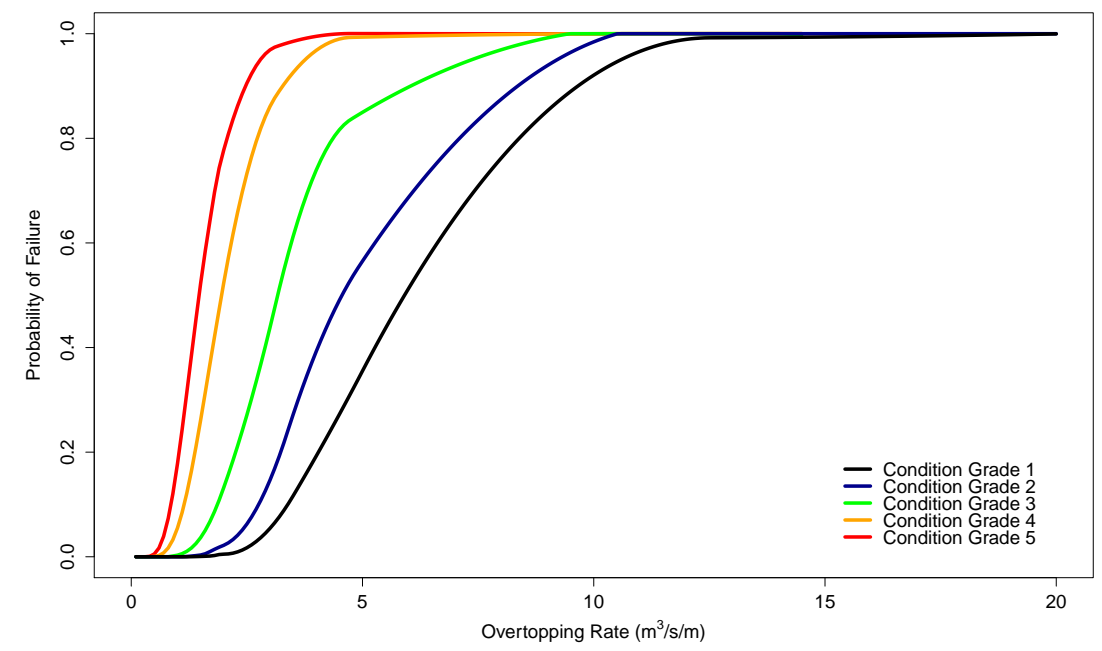

Figure 2: Generic fragility curves used to represent the fragility of the Chesil Cove seawall in existing FRA. 


\section{New Representation}

For vertical walls fronted by shingle beaches the scour predictor derived by Powell and Lowe (1994) is consistently recommended (Defra/EA, 2012) for estimating the response of the beach elevation at structure's toe to a loading event. Based on a laboratory experiment consisting of 3000 normally-incident irregular waves it gives the expected scour depth conditionally on the wave height $H_{s}$, mean wave length $L_{m}$ and water depth at the toe of a structure $d$ in the form of a parametric plot, Figure 3. The laboratory tests were conducted at the 1:17 scale with shingle that corresponds to $5 \mathrm{~mm}<D_{50}<30 \mathrm{~mm}$ at full scale. The shingle size on Chesil beach increases towards the east of the beach reaching a maximum of $D_{50}=50 \mathrm{~mm}$ at Chiswell (Carr, 1969). Thus the predictions give by the plot will give a conservative estimate of the scour depth.

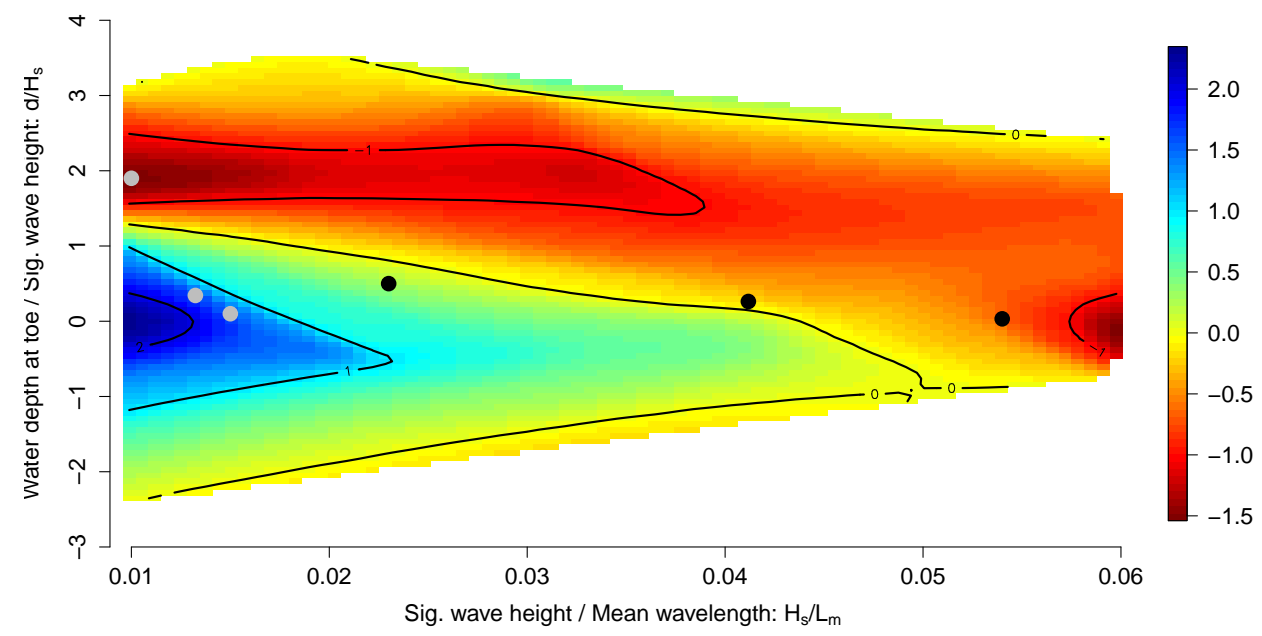

Figure 3: Parametric plot of the predicted level of scour (erosion) and accretion given in terms of dimensionless scour $S_{3000} / H_{s}$ expected adjacent to a vertical wall on a shingle beach (Powell and Lowe, 1994). Two regions of scour are clearly visible one when the waves are breaking at the wall $\left(d=2 H_{s}\right)$ and another when $-0.5 \leq d / 2 H_{s} \geq 0.5$ whilst storm waves are present $\left(H_{s} / L_{m}>\right.$ 0.048). Identically coloured points indicate loading conditions that give rise to equal volumes of overtopping discharge.

The parametric plot reveals the complex relationship between hydraulic loading conditions that the wall is subjected to and the change in the level of the shingle at the toe of the structure. Superimposed onto the plot are points which produce equal volumes of overtopping discharge. They demonstrate that the changes in the level of the beach at the toe can vary greatly for conditions that give rise to equal overtopping discharge volumes, with conditions that give identical overtopping rates often giving rise to both scour and accretion. It is therefore impossible to accurately capture the probability of the defence failing through a scour failure mechanism by using overtopping discharge as the single loading parameter. Thus expressing the failure explicitly conditional 
on each of the loadings is ultimately required if an accurate representation of the fragility is to be attained.

Due to restrictions in the human brains ability to visual any dimension greater than 3, the probability can only graphically be depicted as simultaneously conditional on two variables with any remaining variables required to be fixed at an appropriate values. A selection of fragility surfaces where the probability of failure is displayed simultaneously conditional on the significant wave height and wave period $T_{m}$ where $T_{m}^{2}=\frac{2 \pi L m}{g}$ at a fixed water level for the Chesil Cove seawall is shown in figure 4. By plotting the surfaces at a selection of water levels it is evolution of the walls fragility during the course of a tidal cycle. In this instance it is interesting to note the the second failure region waves break onto the wall develops as the water level increases.

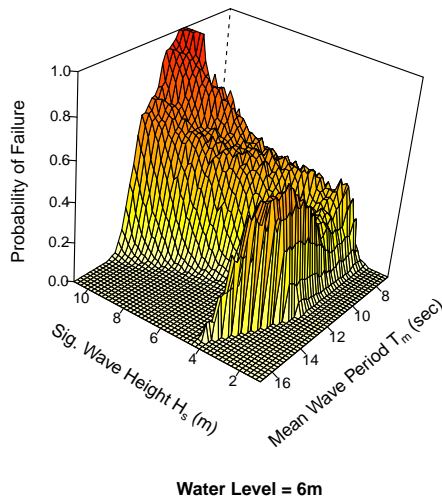

(a)

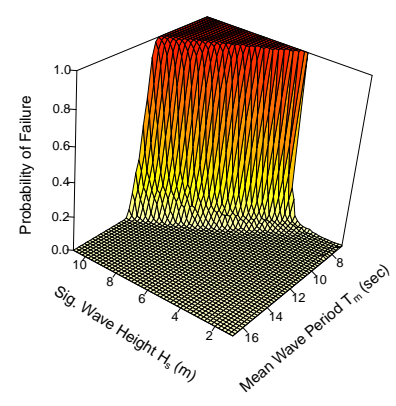

(c)

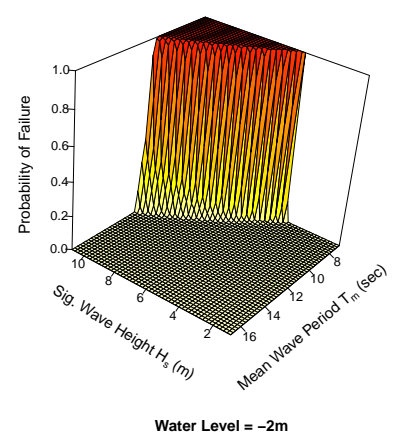

(e)

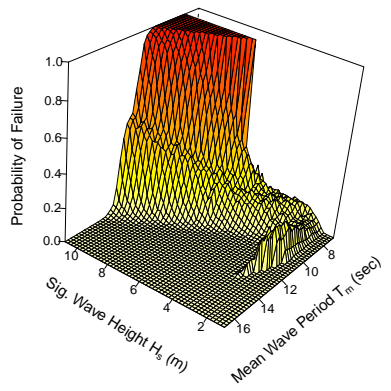

Water Level $=4 \mathrm{~m}$

(b)

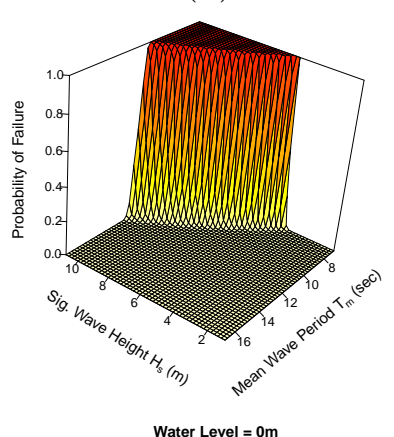

(d)

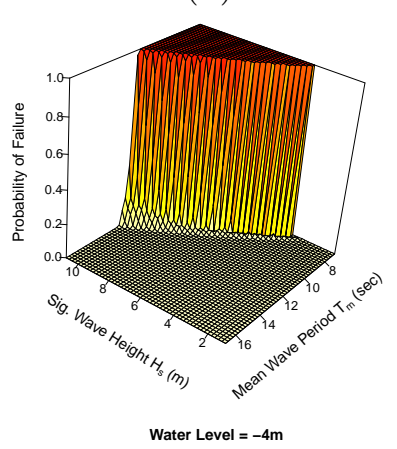

(f)

Figure 4: Multidimensional representation of the fragility of the seawall at Chesil Cove. 
In contrast to the generic curves where the only information relating to the structure specifically is through the visually assigned condition grade which provides a very rough definition of the defence's structural integrity, the new multivariate representation incorporates structurally specific information in its derivation process. It includes the exact dimensions of the structure as well as information on the distribution of the shingle level at the toe from lidar surveys carried out by the CCO. To gauge the increase in accuracy in the assessment of the structures vulnerability by including structurally specific information and moving into the multidimensional domain the predicted response of the defence to a range of plausible conditions from each of the different representations need to be found.

\section{Modelling the Hydraulic Load}

The environmental/atmospheric conditions including the wave data in this study are provided by the European Centre for Medium-Range Weather Forecasts (ECMWF) ERA-Interim Daily model (Dee et al., 2011), a global atmospheric reanalysis. The realaysed wind fields and atmospheric components at 6 hourly intervals are fed into the ocean-wave part of the forecast model, a modified version of the WAM approach (Komen et al., 1994), from which information on the sea state is obtained. Sea level data (astronomical tide + surge residual) in the from of hourly time series from tide gauges at Weymouth both maintained by the UK National Tide Gauge Network were used in the analysis. Data on all of the relevant aspects of the from both sources is available at 6 hourly intervals between the 1st January 1995 and the 31st December 2014, thus the conditions that persist between these dates will be used to in the modelling.

In order to obtain plausible set of multivariate hydraulic loading conditions it is crucial that the dependence structure between the individual loadings is accurately captured. Gouldby et al. (2014) proposed a methodology for simulating nearshore wave conditions for a flood risk analysis. The multivariate extreme value model in Heffernan and Tawn (2004) (HT04) forms the backbone of the approach. Having previously been applied to offshore loading conditions by (Jonathan et al., 2013a; Jonathan and Ewans, 2013; Jonathan et al., 2013b) it adopts a conditional approach to modeling that removes these restrictive assumptions meaning it is more capable to accurately encapsulate the dependence structure between a set of variables than its predecessors. It is again employed here to model the joint distribution of the (offshore) significant wave height $\left(\mathrm{H}_{s}\right)$, surge $(\mathrm{S})$ and wind speed $(\mathrm{U})$ three closely related components of the hydraulic load. The complete structure of the model is shown in Table 1. 
Table 1: Model structure

\begin{tabular}{cc}
\hline Variable & Distribution \\
\hline Significant Wave Height $\left(\mathrm{H}_{s}\right)$ & HT04 \\
Wave Period $\left(\mathrm{T}_{m}\right)$ & Empirical conditional on $\mathrm{H}_{s}$ \\
Surge $(\mathrm{S})$ & HT04 \\
Wave Direction $(\theta)$ & Empirical \\
Wind Speed $(\mathrm{U})$ & HT04 \\
Wind Direction $\left(\theta_{u}\right)$ & Empirical \\
Tide $(\mathrm{AT})$ & Empirical conditional on S and month \\
\hline
\end{tabular}

A separation period of at least 3 days between successive events is set to ensure each of the events are independent, an assumption required for fitting the univariate extreme value statistical models in the HT04 model. The threshold is then set to retain the highest $20 \%$ of the events. The set of independent extreme hydraulic loading events are shown in the figure below. It consisted of 382 events occurring over a period of 19 years, approximately 20 events per year. Thus, for a sample representative of a period of 10,000 years, 200000 realizations of the model are required. These can be simulated by the approach outlined in .

Once the offshore conditions are obtained to conditions encounter by the structure the conditions need to be propagated into the nearshore. As in (Gouldby et al., 2014), SWAN (Booij et al., 1999) a third generation spectral wave model was set up to transform the waves to the nearshore. It is impractical due to the computational intensity of the physics based model to run every case through SWAN. By selecting an appropriate subset of offshore points and constructing a meta-model to emulate the nearshore wave transformation process it possible to limit number of times it is necessary run the SWAN whilst retaining the required accuracy in the results, as shown by (Camus et al., 2011a) using a radial basis function meta model. A subset of offshore conditions were then found using the Maximum Dissimilarity Algorithm (MDA) (Kennard and Stone, 1969) which has been shown to outperform other clustering methods where all areas of the sample space need to be represented in the sample (Camus et al., 2011b) to obtain set of offshore conditions to be run through SWAN. A set of 200 offshore conditions was found to give sufficient coverage of the sample space. The set of nearshore conditions shown in Figure 5. 

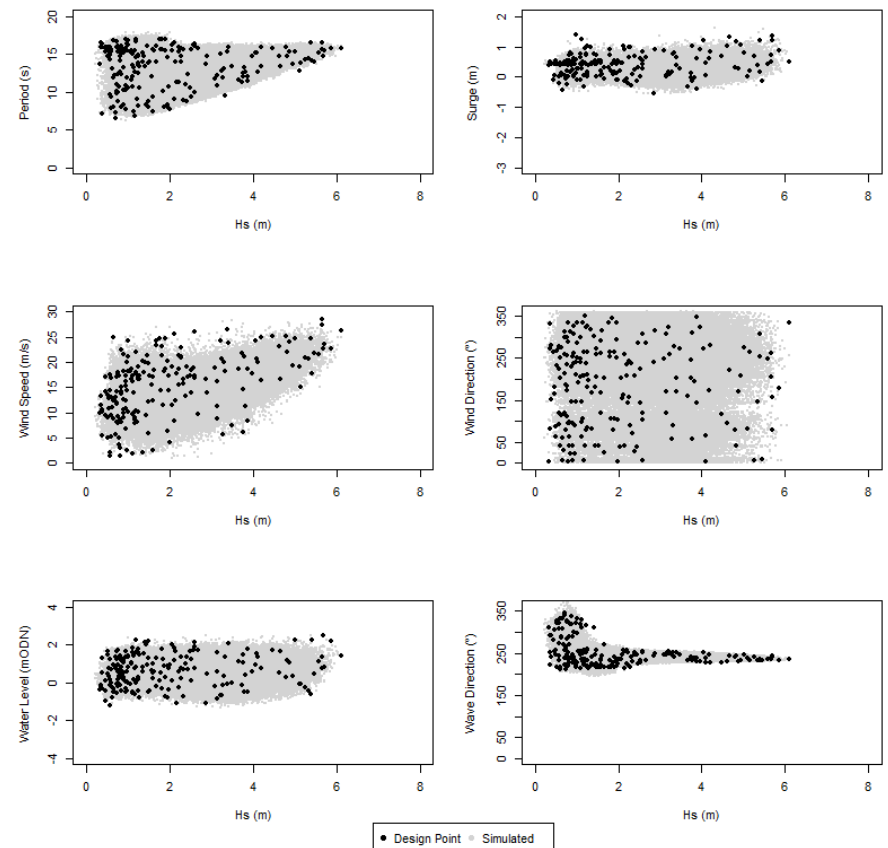

Figure 5: Simulated nearshore conditions obtained by SWAN in the case of the design points and the meta-model for the remaining (simulated) points

\section{Annual Failure Probabilities}

The annual failure probabilities (AFP's) are obtained through a Monte-Carlo simulation procedure. For a given loading event described by $\mathbf{x}_{j}^{\text {Nearshore }}$ a vector of nearshore loading conditions, the seawall can exist in one of two possible states; failed or non-failed. To determine the defence state for a given event, the probability of the defence failing given the loading is retrieved from the appropriate fragility representation. For the univariate fragility representations the significant wave height at the toe of the structure is predicted using the formula derived in Goda (1975) for irregular wave breaking and the overtopping discharge by the equations for vertical structures given in Pullen et al. (2007). Once the conditional failure probability is found, a uniform $[0,1]$ random variate is simulated, if it is less than the obtained conditional failure probability then the defence is assumed to have failed otherwise it is considered to be in a non-failed state. The procedure is carried out for each offshore condition from which the AFP can be estimated.

This process was repeated a large number of times to yield the average annual failure probabilities given in Table 3 . It illustrates that even compared with the univariate fragility descriptions when the defence is lowest condition grade i.e if the defence is considered to be in its worst possible condition by shifting to a multidimensional description of the loadings and fragility the AFP increases by $42 \%$. Although the highly non-linear due to among other factors the topography of the land extent to which flood event can infiltrate the flooding area and the distribution of assets in the area it is likely that such a change in the will have an impact on the flood risk estimates. 
Table 2: Annual failure probabilities obtained using the different representations of fragility.

\begin{tabular}{ccc}
\hline Representation & Average AFP \\
\hline \multirow{4}{*}{ Curve } & Condition Grade 1 & 0 \\
& Condition Grade 2 & 0 \\
& Condition Grade 3 & 0.0001 \\
& Condition Grade 4 & 0.0015 \\
& Condition Grade 5 & 0.0046 \\
\hline Surface & Site Specific & 0.0064 \\
\hline
\end{tabular}

\section{Conclusion}

The magnitude of the flood risk of a given area is highly sensitive to the performance of the flood defence assets that defend the area. Accurate assessment of their fragility is therefore essential for reliable FRA. The work presented in this paper has shown, for a particular structure, significantly different fragility estimates are obtained by considering each of the loading variables explicitly rather than in the form of an amalgamated measure and incorporating site specific information in place of considering a generic structure. The representation used in the existing analysis have been shown to underestimate the defenses fragility. Consequently when estimating the flood risk using the SPR approach the defence can be expected to fail less frequently than it would in reality and hence gives the potential for underestimation of the flood risk estimates.

The next step of the research is to derive multivariate fragility representations for a range of defence types. It will provide an opportunity to more rigorously assess the improvement in the assessment of the fragility by moving into the multidimensional domain. If a similar level of improvement is achieved and the additional computational burden required to do so is none too great, it is envisaged that such representations can be subsumed into the existing FRA tools.

\section{Acknowledgments}

The authors are indebted to the Chanel Coastal Observatory (CCO) for their freely available wave buoy and lidar data, the ECMWF for the the ERAInterim data and British Oceanographic Data Center (BODC) for providing information on the water level. The authors would also like to thank the SWAN group at Delft University of Technology for providing the freely available wave propagation model and the Engineering and Physical Sciences Research Council (EPSRC) for their contribution to the funding of the project. 


\section{References}

Booij, N., Ris, R. C., and Holthuijsen, L. A third-generation wave model for coastal regions, model description and validation. Journal of Geophysical Research, (C4):7649-7666, 1999.

Camus, P., Mendez, F. J., and Medina, R. A hybrid efficient method to downscale wave climate to coastal areas. Coastal Engineering, 58(9):851862, 2011a.

Camus, P., Méndez, F. J., Medina, R., and Cofño, A. S. Analysis of clustering and selection algorithms for the study of multivariate wave climate. Coastal Engineering, 58(6):453-462, 2011b.

Carr, A. Size grading along a pebble beach: Chesil beach. england. Journal of Sedimentary Petrology, 39:297-311, 1969.

Dee, D. P., Uppala, S. M., Simmons, A. J., Berrisford, P., Poli, P., Kobayashi, S., Andrae, U., Balmaseda, M. A., Balsamo, G., Bauer, P., Bechtold, P., Beljaars, A. C. M., van de Berg, L., Bidlot, J., Bormann, N., Delsol, C., Dragani, R., Fuentes, M., Geer, A. J., Haimberger, L., Healy, S. B., Hersbach, H., Hólm, E. V., Isaksen, L., Kllberg, P., Khler, M., Matricardi, M., McNally, A. P., Monge-Sanz, B. M., Morcrette, J.-J., B.-K., P., Peubey, C., de Rosnay, P., Tavolato, C., Thpaut, J.-N., and Vitart, F. The era-interim reanalysis: configuration and performance of the data assimilation system. Quarterly Journal of the Royal Meteorological Society, 137:553-597, 2011.

Defra EA. R \& d technical report fd2318/tr1 - performance and reliability of flood and coastal defences. Technical report, Defra/EA Joint R\& D FCERM Programme, 2005.

Defra/EA. Toe structures management manual. 2012.

Goda, Y. Irregular wave deformation in the surf zone. Coastal Engineering in Japan, 18:13-26, 1975.

Gouldby, B., Sayers, P., Mulet-Marti, J., Hassan, M. A. A. M., and D., B. A methodology for regional-scale flood risk assessment. Proceedings of the ICE - Water Management, 161:169-182, 2008.

Gouldby, B., Méndez, F., Guanche, Y., Rueda, A., and Mínguez, R. A methodology for deriving extreme nearshore sea conditions for structural design and flood risk analysis. Coastal Engineering, 88:15-26, 2014.

Hall, J. W., Dawson, R. J., Sayer, P. B., Rosu, C., Chatterton, J. B., and Deakin, R. A methodology for national-scale flood risk assessment. In Proceedings of the Institution of Civil Engineers - Water $\&$ Maritime Engineering, volume 156, pages 235-247, 2003.

Heffernan, J. E. and Tawn, J. A. A conditional approach for multivariate extreme values. Journal of the Royal Statistical Society. Series B (Statistical Methodology), 66(3):497-546, 2004. 
Jonathan, P. and Ewans, K. Statistical modelling of extreme ocean environments for marine design: a review. Ocean Engineering, 62(0):91-109, 2013.

Jonathan, P., Ewans, K., and Randell, D. Joint modelling of extreme ocean environments incorporating covariate effects. Coastal Engineering, 79(0): 22-31, 2013a.

Jonathan, P., Flynn, J., and Ewans, K. Joint modelling of wave spectral parameters for extreme sea states. Ocean Engineering, 37(11):1070-1080, 2013b.

Kennard, R. W. and Stone, L. A. Computer aided design of experiments. Technometrics, 11:137-148, 1969.

Komen, G. J., Cavaleri, L., Donelan, M., Hasselmann, K., Hasselmann, S., and Janssen, P. A. E. M. Dynamics and Modelling of Ocean Waves. Cambridge University Press, 1994. ISBN 9780511628955. Cambridge Books Online.

Powell, K. and Lowe, J. The scouring of sediments at the toe of seawalls. In Proceedings of the Hornafjordur International Coastal Symposium, Iceland June 20-24- Edited by Gisli Viggosson, pages 749-755, 1994.

Pullen, T., Allsop, N. W. H., Bruce, T., van der Meer, J. W., Schüttrumpf, H., and Kortenhaus, A. Eurotop: Wave overtopping of sea defences and related structures: Assessment manual. 2007.

Sayers, P. B., Hall, J., and Meadowcroft, I. C. Towards risk-based flood hazard managment. Proceedings of ICE - Civil Engineering, 150(5):36-42, 2002.

Sayers, P. and Meadowcroft, I. Rasp - a hierarchy of risk-based methods and their application. In 40th Defra Flood and Coastal Management Conference, York, UK. 5 - 7 July, 2005.

Schultz, M., Gouldby, B., Simm, J., and Wibowo, J. Beyond the factor of safety: Developing fragility curves to characterize system reliability, 2010.

Simm, J., Gouldby, B., P.Sayers, Flikweert, J., Wersching, S., and Bramley, B. Representing fragility of flood and coastal defences: getting into the detail. In Flood Risk Management: Research into Practice (FLOODrisk 2008), pages 621-631. London: Taylor \& Francis, 2008.

Sutherland, J., Obhrai, C., Whitehouse, R., and Pearace, A. Laboratory tests of scour at a seawall. In 3rd international conference on scour and erosion, 2006 .

USACE . Risk-based analysis of flood damage reduction studies. Technical report, US Army Corp of Engineers (USACE), Washington DC, 1996.

USACE . Risk-based analysis and uncertainty in flood damage reduction studies. Technical report, US Army Corp of Engineers (USACE), Washington DC, 2000. 